\title{
Persistent glucocorticoid resistance in systemic lupus erythematosus patients during clinical remission
}

\author{
A.K.G. Melo' ${ }^{1}$ M.R. Melo ${ }^{2}$, A.B.A. Saramago', G. Demartino ${ }^{2}$, \\ B.D.B. Souza ${ }^{1}$ and C.A. Longui ${ }^{2}$ \\ ${ }^{1}$ Unidade Reumatologia, Departamento de Medicina Interna, \\ Irmandade da Santa Casa de Misericórdia de São Paulo, São Paulo, SP, Brasil \\ ${ }^{2}$ Laboratório de Medicina Molecular, Departamento de Ciências Fisiológicas, \\ Faculdade de Ciências Médicas, Santa Casa de São Paulo, SP, Brasil \\ Corresponding author: A.K.G. Melo \\ E-mail: anakarla-guedes@bol.com.br
}

Genet. Mol. Res. 12 (2): 2010-2019 (2013)

Received March 3, 2012

Accepted September 16, 2012

Published February 19, 2013

DOI http://dx.doi.org/10.4238/2013.February.19.1

\begin{abstract}
Glucocorticoids (GCs) are key drugs in the treatment of systemic lupus erythematosus (SLE). GC dose reduction during remission is related to disease activity, GC dose used, length of treatment, and individual GC sensitivity. We compared GC receptor $\alpha(\mathrm{GR} \alpha)$ isoform and nuclear factor kappaB (NF- $\kappa \mathrm{B})$ messenger RNA quantitation and in vivo $\mathrm{GC}$ sensitivity between SLE patients during remission and healthy controls. We performed a cross-sectional study of 19 women aged 22-49 years, including 9 SLE patients in clinical remission taking $\leq 5 \mathrm{mg}$ prednisone and 10 matched controls. We evaluated GC sensitivity using 2 cortisol suppression tests: a very-low-dose intravenous dexamethasone suppression test (VLD-IV-DST) and a low-dose oral dexamethasone suppression test. GR $\alpha$ and NF- $\mathrm{NB}$ mRNA were quantified using real-time polymerase chain reaction. Although basal cortisol and adrenocorticotropic hormone levels were similar between the groups, the percentage of cortisol reduction after the VLD-IV-DST was $56 \%$ lower in SLE patients than in controls $(\mathrm{P}=0.014) . \mathrm{GR} \alpha$ and NF- $\kappa \mathrm{B}$
\end{abstract}


gene expression levels were similar between the groups. The low-dose oral dexamethasone test caused intense cortisol suppression in all individuals, limiting the ability of this test to discriminate individual GC sensitivity. A positive correlation was found between the extent of cortisol suppression in vivo (VLD-IV-DST) and the number of days elapsed since the last flare of lupus activity. Despite clinical remission, SLE patients displayed partial GC resistance recognized by the VLD-IV-DST. The mechanism of this resistance is unrelated to altered GR $\alpha$ and NF- $\mathrm{kB}$ mRNA expression.

Key words: Cortisol; Dexamethasone; Glucocorticoid sensitivity; Systemic lupus erythematosus

\section{INTRODUCTION}

Systemic lupus erythematosus (SLE) is an autoimmune inflammatory disease characterized by alternate periods of exacerbation and remission. The pathogenesis is complex, and the target tissue damage is caused primarily by autoantibodies and immune complexes. The abnormal immune response determines the persistence of pathogenic B and T cells (Oelke and Richard, 2002).

High doses of glucocorticoids (GCs) are used to treat severe manifestations of SLE. However, some patients may be unresponsive to GCs or may respond initially but relapse when the GC dose is tapered. Additionally, toxic GC side effects are virtually universal when high doses are needed for long periods. GC dose reduction schemes during SLE remission are largely empirical and related to disease activity, GC dose used, length of treatment, clinical symptoms, and individual GC sensitivity. Elucidating the mechanisms involved in GC resistance in SLE patients is important not only to understand more fully the pathophysiology of the disease but also to identify potential treatment protocols directed at the modulation of pro-inflammatory factor expression and improvement of patient responsiveness to GCs or other medications.

In recent years, transcription factors nuclear factor kappaB (NF- $\mathrm{kB})$ and activator protein 1 have been discovered to be crucial for the induction of genes involved in inflammation as well as in a wide range of diseases. These factors are present in chronic activation of the immune system, such as that in asthma, atherosclerosis, inflammatory bowel disease, and autoimmune diseases including multiple sclerosis and rheumatoid arthritis (RA) (De Bosscher et al., 2001). More recently, adaptor proteins such as transforming growth factor-activated kinase $1, \mathrm{NF}-\mathrm{\kappa B}$-inducing kinase, and mitogen-activated protein kinase kinase have been shown to be capable of phosphorylating the inhibitor of NF- $\mathrm{kB}$ kinase (IKK) complex and triggering its dissociation. This process leads to the activation of the IKK-NF- $\mathrm{kB}$ pathway, inducing tissue inflammation (Beck et al., 2009).

Our previous research (Cobra et al., 2009) suggested that the mechanisms involved in GC resistance in RA do not occur at the GC receptor alpha (GR $\alpha$ ) messenger RNA (mRNA) level but as a post-receptor adaptive response. Another study (Cavalcante et al., 2010) has shown that GC sensitivity evaluated by the percentage of cortisol reduction after a very-low-dose intravenous dexamethasone suppression test (VLD-IV-DST), as well as NF-kB, IKK, c-Fos (proto-oncogene), and GR $\alpha$ mRNA expression, were similar in RA patients and controls.

The aim of this study was to determine and compare expression of GR $\alpha$ and NF- $\mathrm{KB}$ mRNA in SLE patients in clinical remission and healthy controls and to correlate their levels with GC sensitivity as assessed by a VLD-IV-DST and low-dose oral dexamethasone suppression test. 


\section{MATERIAL AND METHODS}

\section{Selection of subjects}

We studied 9 individuals under treatment at the Rheumatology Clinic of the Internal Medicine Department of Irmandade da Santa Casa de Misericórdia de São Paulo who fulfilled the SLE classification criteria of the American College of Rheumatology (1997) (Hochberg, 1997). All SLE patients were in remission and were either not receiving prednisone treatment (3 patients) or were receiving a maximum dose of $5 \mathrm{mg} /$ day.

The control group consisted of 10 apparently healthy individuals selected through clinical evaluation by history and physical examination to match subjects in the SLE group with respect to gender (all were female) and age [means \pm standard deviation (SD)] in the SLE group $=$ $30.6 \pm 2.4$ years and in controls $34 \pm 3.5$ years; $\mathrm{P}=0.44$. We also noticed that mean $\pm \mathrm{SD}$ weight was similar among the groups: $69 \pm 4.5 \mathrm{~kg}$ in patients and $63.9 \pm 3 \mathrm{~kg}$ in controls $(\mathrm{P}=0.356)$.

We excluded controls and SLE patients who were younger than 18 years, had acute or chronic illnesses such as endocrine disease, asthma, and inflammatory bowel disease, or had used drugs that can accelerate dexamethasone metabolism (such as phenytoin and barbiturates) during the previous 4 months, as well as those who had a basal cortisol level of $<7 \mu \mathrm{g} / \mathrm{dL}$ to assure that the hypothalamic-pituitary-adrenal axis was not suppressed. The study protocol was approved by the Local Institutional Ethics Committee, and all individuals signed a written consent form before inclusion in the study.

\section{Clinical characteristics of SLE patients}

All SLE patients had an SLE Disease Activity Index (Gladman et al., 2002) score of 0. The mean \pm SD duration of SLE was $7.3 \pm 5.1$ years. The mean age at SLE diagnosis was $26.7 \pm$ 8 years. The average time since the last flare of lupus activity was $840.8 \pm 572.4$ days. All lupus patients had a positive antinuclear autoantibody test (Arbuckle et al., 2003) and had arthritis. None of the patients had a history of aggressive manifestations of the disease, such as cerebrovascular events, thromboembolic complications, or severe kidney or hematologic involvement. Six patients were using oral prednisone at a daily dose of $5 \mathrm{mg}$ along with hydroxychloroquine ( $400 \mathrm{mg} / \mathrm{day})$ or diphosphate of chloroquine $(250 \mathrm{mg} /$ day). Two patients used only an antimalarial drug (chloroquine, $250 \mathrm{mg}$ daily), and one used only enalapril for the treatment of systemic arterial hypertension. End-organ damage was demonstrated in 4 patients and was quantified by the Systemic Lupus Index of the Consensus Committee/American College of Rheumatology (Rahman et al., 2001).

\section{VLD-IV-DST and low-dose oral dexamethasone suppression test}

All patients and controls underwent a VLD-IV-DST $\left(20 \mu \mathrm{g} / \mathrm{m}^{2}\right)$. We recently described the use of this test for the recognition of individual GC sensitivity in various age groups (Faria et al., 2008). Briefly, after a fasting period of 10-12 h and $30 \mathrm{~min}$ of rest, a blood sample was obtained for cortisol and adrenocorticotropic hormone (ACTH) measurements. Peripheral blood mononuclear cells (PBMCs) were obtained at the same time. Afterward, individuals of both groups received disodium phosphate dexamethasone intravenously (Decadron ${ }^{\circledR}, 2 \mathrm{mg} / \mathrm{mL}$, Prodome Chemical and Pharmaceutical, São Paulo, SP, Brazil) at a dose of $20 \mu \mathrm{g} / \mathrm{m}^{2}$ body sur- 
face area as a bolus. A subsequent blood sample was taken 120 min later for cortisol and ACTH measurement (Immulite 2000 Cortisol, DPC, Los Angeles, CA, USA, and IMMULITE ${ }^{\circledR} 2000$ $\mathrm{ACTH}$, Siemens Healthcare, Llanberis, UK). The in vivo assessment of pituitary GC sensitivity was represented by the percentage of cortisol reduction (F\%) after VLD-IV-DST.

The recognition of hypercortisolism is usually identified using an oral low-dose dexamethasone test. We compared the accuracy of this test to that of the VLD-IV-DST to identify GC sensitivity. All individuals received dexamethasone orally at a dose of $20 \mu \mathrm{g} \cdot \mathrm{kg}^{-1} \cdot \mathrm{day}^{-1}$ (every $6 \mathrm{~h}$ ) for 2 consecutive days, when a new blood sample was obtained for cortisol and ACTH measurements. The expected response of normal controls to the test is cortisol $<1.8$ $\mu \mathrm{g} / \mathrm{dL}$ and $\mathrm{ACTH}<20 \mathrm{pg} / \mathrm{mL}$ when the samples are collected after 2 days of dexamethasone administered every $6 \mathrm{~h}$ (Liddle, 1960).

\section{GR $\alpha$ and NF- $\kappa B$ mRNA determination through real-time quantitative polymerase chain reaction (PCR)}

A 20-mL venous blood sample was collected from each subject in tubes containing ethylenediaminetetraacetic acid K3 (Vacutainer, Becton-Dickinson, Franklin Lakes, NJ, USA). PBMCs were obtained after the addition of $20 \mathrm{~mL}$ Histopaque ${ }^{\circledR} 1077$ (Sigma, USA) and centrifugation for $30 \mathrm{~min}$ at $800 \mathrm{~g}$, according to manufacturer recommendations. Total RNA was isolated from cells using guanidinium thiocyanate-chloroform extraction (Trizol, Invitrogen, USA). Complementary DNA (cDNA) was synthesized from $1 \mu \mathrm{g}$ total RNA using a reverse transcription reaction (TaqMan Reverse Transcription Reagents, Applied Biosystems).

$\mathrm{NF}-\mathrm{\kappa B}$ and GR $\alpha$ mRNA were determined according to our previously published protocol (Sousa e Silva et al., 2010). Briefly, real-time PCR was performed for these genes and the breakpoint cluster region (BCR) gene as a normalizing gene. Primers and probes were as

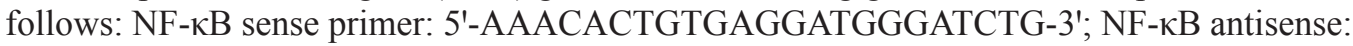
5'-CGAAGCCGACCACCATGT-3'; GR $\alpha$ sense primer: 5'-GAAGGAA ACTCCAGCCAGA A-3'; GR $\alpha$ antisense primer: 5'-CAGCTAACATCTCGGGGAAT-3'; GR $\alpha$ probe: 6-FAM 5'-GCTTCCAAACATTTTTGGATAAGACCAT-3' - TAMRA; BCR sense primer: 5'-CCTTCG ACGTCAATAACAAGGAT-3'; BCR anti-sense primer: 5'-CCTGCGATGGCGTTC AC-3'; BCR probe: 6-FAM - 5'-TCCATCTCGCTCATCATCACCGACA-3' - TAMRA.

In each PCR run, we used a standard curve of serial dilutions of cDNA obtained from a standardized Jurkat (E6-1 clone, ATCC) cell culture. Real-time quantitative PCR conditions were the same for both the GR $\alpha$ and the BCR genes as described elsewhere (Melo et al., 2004) and were carried using a TaqMan PCR Core kit (Applied Biosystems). Briefly, 1X TaqMan buffer A, $500 \mathrm{mM}$ of each deoxyribonucleotide triphosphate, $4.5 \mathrm{mM} \mathrm{MgCl}_{2}, 200 \mathrm{nM}$ of each primer, $100 \mathrm{nM}$ probe, $0.025 \mathrm{U} / \mathrm{mL}$ AmpliTaq Gold, $2 \mu \mathrm{L} \mathrm{cDNA}$, and water were incubated in a total volume of $23 \mu \mathrm{L}$. SYBR Green, an intercalating, nonspecific dye detection system was used for the quantitation of NF$\kappa \mathrm{B}$. For NF- $\mathrm{kB}$, primer concentrations were adjusted to $0.3 \mu \mathrm{L}$ of each primer (final concentration, $120 \mathrm{nM})$, with a corresponding increase in water $(9.9 \mathrm{~mL})$ in each reaction (Cavalcante et al., 2010).

Cycle conditions on an ABI 7500 (Applied Biosystems) were the same for all genes: $95^{\circ} \mathrm{C}$ for $10 \mathrm{~min}$ (AmpliTaq Gold or Taq Platinum activation) followed by 45 cycles of $95^{\circ} \mathrm{C}$ for $15 \mathrm{~s}$ (denaturation) and $60^{\circ} \mathrm{C}$ for $90 \mathrm{~s}$ (annealing and extension). When SYBR Green detection was used, a final dissociation stage was included, and melting curves were analyzed to ensure specific amplification. 


\section{Statistical analysis}

Calculations of expression units for GR $\alpha$ and NF-kB with BCR normalization were performed in MS-Excel 2000 for Windows (Microsoft, Redmond, WA, USA). Statistical analyses were carried out using SigmaStat for Windows v.3.05 (SPSS, Chicago, IL, USA) with the level of significance set at $\mathrm{P}<0.05$. For comparison of quantitative variables, we used the Student $t$-test (when normal distribution was confirmed by the Kolmogorov-Smirnov test) or the Kruskal-Wallis test. We compared proportions of qualitative variables using the chi-square test. Linear regression analysis was used to compare continuous variables and $\mathrm{F} \%$. In the evaluation of a continuous variable in 2 instances in the same individual, we used a paired $t$-test or the Wilcoxon signed-rank test. In lupus patients, the identification of variables that are associated to $\mathrm{F} \%$ was demonstrated by multivariate linear regression analysis (backward stepwise linear regression, $\mathrm{F}$ to remove $=3.9$ ).

\section{RESULTS}

\section{Comparison of GC sensitivity}

Basal median cortisol concentrations were similar in SLE patients and controls (11.7 and $19.4 \mu \mathrm{g} / \mathrm{dL}$, respectively; $\mathrm{P}=0.25$ ). Basal ACTH concentrations were also similar between the groups (Table 1).

Table 1. Basal cortisol and adrenocorticotropic hormone (ACTH) concentrations, glucocorticoid sensitivity and glucocorticoid receptor $\alpha(\mathrm{GR} \alpha)$, and nuclear factor kappaB (NF- $\mathrm{kB})$ mRNA quantitation in patients with systemic lupus erythematosus (SLE) and controls.

\begin{tabular}{|c|c|c|c|}
\hline & SLE & Controls & $\mathrm{P}$ \\
\hline Basal cortisol* & $11.7(9.9-13.3)$ & $19.4(10-26.2)$ & 0.25 \\
\hline Basal ACTH** & $24.1(9.9)$ & $17.7(17.3)$ & 0.33 \\
\hline $\mathrm{F} \% *$ & $23.5(-10-47.9 \%)$ & $53.2(42-58.6 \%)$ & 0.014 \\
\hline FOr $\% *$ & $94.8(78.9-95.6 \%)$ & $93.9(90.8-98.1 \%)$ & 0.41 \\
\hline GR $\alpha$ mRNA* & $16.8(9.5-32.4)$ & $11.7(7.1-128.1)$ & 0.77 \\
\hline NF-кB mRNA* & $29.2(11-198.9)$ & $32.0(2.6-197.6)$ & 0.67 \\
\hline
\end{tabular}

F\% = cortisol suppression after 120 min very-low-dose intravenous dexamethasone suppression test [(VLD IV-DST); 2 patients presented increased cortisol concentrations at $120 \mathrm{~min}$ after VLD IV-DST, thus having negative F\%]; FOr $\%=$ cortisol suppression after 2 days of oral dexamethasone. *Data are reported as median (p25-p75), KruskalWallis. **Data are reported as means (standard deviation) $t$-test.

After performing the low-dose oral dexamethasone suppression test with the VLD-IVDST, we observed that the values for cortisol at 120 min were similar in the 2 groups, with means $\pm \mathrm{SD}$ of $10.3 \pm 4.9$ for patients and $8.9 \pm 3.9$ for controls $(\mathrm{P}=0.51)$. However, the extent of cortisol suppression at $120 \mathrm{~min}$ in patients was lower than that in controls (23.5 vs $53.2 \%$, respectively; $\mathrm{P}=$ 0.014). The proportion of individuals who had more than $50 \%$ of cortisol suppression was statistically lower in SLE patients than in the control group ( $0 / 9$ vs $6 / 10$, respectively; $\mathrm{P}=0.001)$.

After 2 days of low-dose oral dexamethasone suppression testing, we found that the extent of cortisol suppression (FOr $\%$ ) was similar in the 2 groups, with a median of $94.8 \%$ for SLE patients and $93.9 \%$ for controls $(\mathrm{P}=0.414)$. To check the discriminatory efficiency of FOr $\%$, we calculated the median suppression in the entire group ( $94.4 \%$ suppression) and compared the number of individuals who suppressed more than the median in each group: 5/10 in controls and 5/9 in SLE patients $(\mathrm{P}=0.81)$. We also checked for agreement between greater response to the oral test 
and VLD-IV-DST (F\% vs FOr\%). Of the 10 individuals who suppressed more than the median in the oral test, only 3 also had more than 50\% suppression in the VLD-IV-DST $(\mathrm{P}=0.876)$.

\section{Comparison of gene expression}

Median mRNA values of GR $\alpha$ and NF-kB were similar in the 2 groups (see Table 1).

\section{Relationship between glucocorticoid sensitivity, gene expression, and clinical findings in SLE patients}

We observed no significant correlation between in vivo GC sensitivity, as assessed by suppression of cortisol after VLD-IV-DST and PBMC expression of GR $\alpha$ or NF- $\mathrm{\kappa B}(\mathrm{r}=$ $8.8 \%, \mathrm{P}=0.324$ and $\mathrm{r}=5.7 \%, \mathrm{P}=0.462$, respectively). Similarly, no significant correlation was detected between FOr $\%$ and expression of $\mathrm{GR} \alpha$ or $\mathrm{NF}-\mathrm{\kappa B}(\mathrm{r}=7.9 \%, \mathrm{P}=0.796$ and $\mathrm{r}=$ $0.9 \%, \mathrm{P}=0.766$, respectively).

The suppression of cortisol after VLD- IV-DST, which reflected pituitary GC sensitivity, did not correlate significantly with basal ACTH and cortisol levels. A multivariate linear regression analysis indicated that increased number of days since the last flare of lupus activity (SLE Disease Activity Index $>6$ ) was the only independent variable correlated with higher GC sensitivity, as evaluated with $\mathrm{F} \%$ using the VLD-IV-DST $(\mathrm{r}=75.6 \%, \mathrm{P}=0.019$; Figure 1).

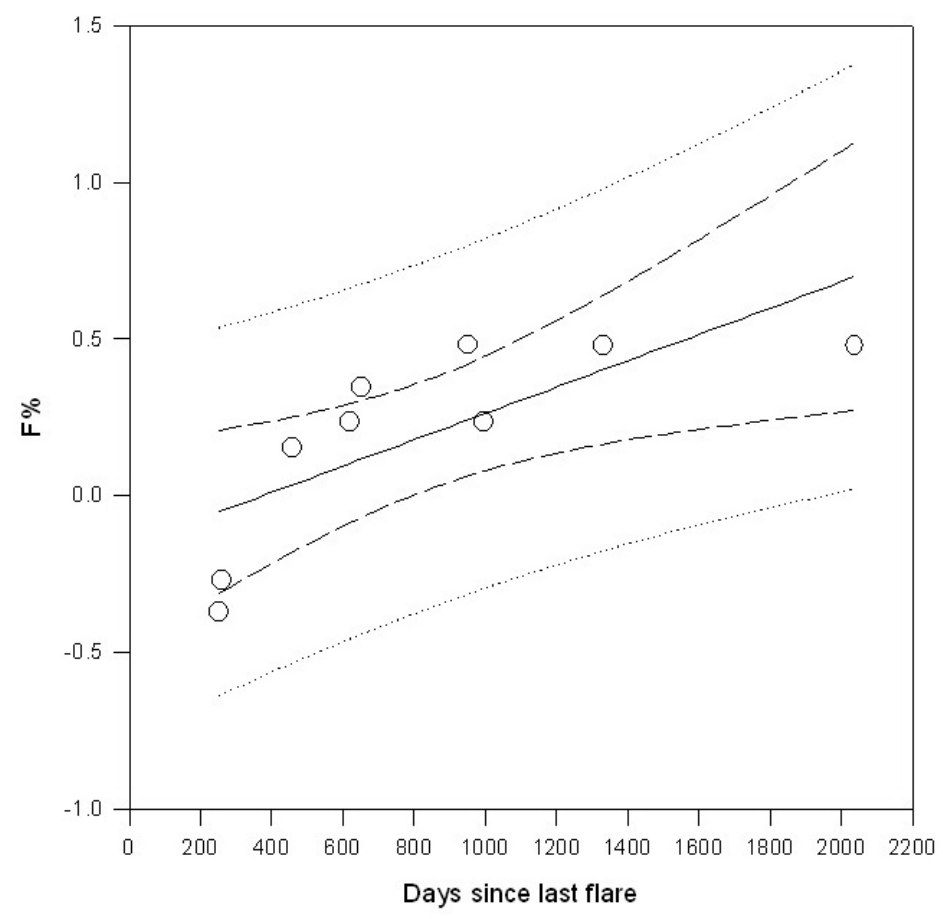

Figure 1. Correlation of the extent of cortisol suppression at $120 \mathrm{~min}(\mathrm{~F} \%)$ and days elapsed since the last flare of lupus activity (SLEDAI $>6)\left(\mathrm{r}=75.6 \%, \mathrm{r}^{2}=57.1 \%, \mathrm{P}=0.019\right)$. Longer periods since last disease flare correlated positively with higher GC sensitivity in SLE patients in remission. 


\section{DISCUSSION}

We studied in vivo GC sensitivity in 9 patients with SLE in clinical remission using the VLD-IV-DST and the mRNA levels of the GR $\alpha$ isoform and NF- $\mathrm{kB}$. Although no restriction was made in relation to gender in the inclusion criteria, the patients were all females. The SLE patients had a mean age at SLE diagnosis of 26.7 years, a figure similar to that found in the literature, which asserts that the age at diagnosis of SLE is generally 15 to 40 years (Petri, 2002). For the present study, we selected SLE patients with a low degree of severity and, therefore, using low doses of prednisone ( $\leq 5 \mathrm{mg}$ /day).

Controls maintained parity by age, gender, weight, and body surface area to patients, allowing an appropriate comparison between groups even with a small number of samples, especially in tests of GC sensitivity. Basal cortisol concentrations were $>7 \mu \mathrm{g} / \mathrm{dL}$, suggesting that the hypothalamic-pituitary-adrenal axis was not suppressed in either group at the time of sample collection (Winter and Harris, 2008). We assumed that expression of GR $\alpha$ and the results of the cortisol suppression tests were not influenced by a negative feedback mechanism or downregulation of GRs.

Analysis of basal cortisol and ACTH in SLE patients and controls showed similar results. After 120 min of VLD-IV-DST, the concentration of cortisol was similar between groups, whereas the ACTH level was lower in the control group. Quantification of ACTH is characterized by known methodological difficulties owing to the sensitivity of the protein to heat and its instability in plasma (Castro and Moreira, 2002). The observed difference may also have been caused by sampling variability owing to the small number of cases in each group.

Significant reduction of ACTH and cortisol concentrations occurred after VLD-IVDST, indicating that this test was effective in establishing a spectrum of sensitivity to GC in vivo as previously demonstrated (Faria et al., 2008; Cobra et al., 2009; Cavalcante et al., 2010). However, the extent of suppression was lower in patients than in controls (23.48 vs $53.2 \%$, respectively), indicating lower GC sensitivity in SLE patients during the remission phase of the disease. Comparing patients and controls for GC sensitivity in vivo after the oral test with dexamethasone revealed no difference between the groups, and we were unable to identify a degree of suppression that differentiated patients from controls. Analysis of cases and controls together to assess the results of cortisol suppression in the VLD-IV-DST and the oral test ( $\mathrm{F} \%$ and $\mathrm{FOr} \%)$ showed no agreement between the 2 tests. This result may indicate that GC suppression at the time of the oral test was too intense (very high FOr\% median) to create an adequate spectrum of response that could identify partial GC resistance.

Similar to studies in RA patients (Neeck et al., 2002; Cobra et al., 2009), our study found no difference between the SLE and control groups in GR $\alpha$ expression in PBMCs. In addition, no correlation occurred between GR $\alpha$ or NF- $\mathrm{KB}$ expression and cortisol suppression after the VLD-IV-DST in patients or controls, which correlates to observations published by Cavalcante et al. (2010). However, RA may present greater differences in inflammation between synovia and PBMCs, and due to the systemic involvement in SLE, PBMC gene expression may better reflect inflammation status. The degree of inflammation in our patients may have been insufficient for the detection of changes in mRNA expression from PBMCs, but another explanation includes the interference of previous chronic use of GCs.

We found that patients with less time since the last flare of SLE activity had a lower GC sensitivity, and this finding was the only variable that correlated with the extent of cortisol 
suppression in vivo, even when multivariate analysis was performed. One explanation is the existence of post-receptor effect - that is, a residual inflammatory process after a disease flare, not mediated by NF- $\mathrm{KB}$, that causes partial GC resistance in the central nervous system. Abnormal translocation of activated GR $\alpha$ to the nucleus, co-inactivation of GR $\alpha$ and AP-1, heterodimerization of GR $\alpha$ with the GR $\beta$ isoform, and altered expression or function of co-activator could be postreceptor interferents that increase GC resistance (Bamberger et al., 1996; Schaaf and Cidlowski, 2003; Matthews et al., 2004; Faria and Longui, 2006; Piotrowski et al., 2007).

Another possible explanation for the partial resistance to GCs in some SLE patients is the enhanced expression of GR $\beta$. Piotrowski et al. (2007) demonstrated greater expression of mRNA GR $\beta$ compared to that of GR $\alpha$ in SLE patients with highly active disease versus patients with low degrees of systemic inflammation. The association of immune-mediated diseases and expression of GR $\beta$ has been studied by several authors, who have described GR $\beta$ acting as a dominant negative inhibitor of GR $\alpha$ and increased expression of this $\beta$ isoform in the PBMCs of GC-resistant patients with asthma (Oakley et al., 1996, 1999; Webster et al., 2001).

Additionally, changes in GR phosphorylation can also explain GC resistance, as exemplified by the increased activity of protein kinases such as c-Jun N-terminal kinase, extracellular-signal-related kinase, and p38 mitogen-activated protein kinase (MAPK). Phosphorylation of the GR-mediated p38 MAPK is linked to a reduction in the activity of GR $\alpha$ transcription. Thus, the GC resistance found in some patients might be reversed by inhibitors of MAPKs ( $\mathrm{Li}$ et al., 2004).

The occurrence of mutations causing GC resistance can cause errors in data interpretation. A study by Lee et al. (2004) reported a silent mutation at codon 766 (exon 9) in 8.3\% of SLE patients. This polymorphism had been shown by Koper et al. (1997) to be correlated to a lowered response to the oral dexamethasone test in elderly patients.

Regarding the NF- $\mathrm{KB}$ activity, a defect in the activation of NF- $\mathrm{kB}-$ mediated T-cell receptors in PBMCs has been identified in SLE patients but not in RA patients and healthy controls (Wong et al., 1999). Expression of NF- $\mathrm{KB}$ is reportedly increased in RA and could be one of the factors involved in disease pathogenesis (Mckay and Cidlowski, 1999). However, describing the impact of alterations on NF- $\mathrm{KB}$ activity in SLE and explaining the numerous immunological abnormalities found in this pleomorphic disease are difficult. A possible explanation for similar NF- $\mathrm{BB}$ gene expression in controls and SLE patients is their low degree of systemic inflammation.

Future studies may evaluate expression of c-Fos, AP-1, and GR $\beta$ and recognize GR polymorphisms to elucidate the mechanisms of partial resistance to GCs in certain patients with SLE. Another consideration is whether SLE patients in remission with increased sensitivity to GC on a VLD-IV-DST may have their doses of prednisone decreased or interrupted without worsening their clinical status.

Despite the limitations of our study, we demonstrated for the first time in patients with SLE in clinical remission using low doses of prednisone that partial GC resistance in vivo was not due to alterations in expression of GR $\alpha$ or NF- $\mathrm{kB}$. We also demonstrated that increased sensitivity to GC in SLE correlates with increased time since the last flare of disease activity.

\section{ACKNOWLEDGMENTS}

We are grateful to the Support Center for Scientific Publications of Santa Casa de São 
Paulo, Faculty of Medical Sciences, for editorial assistance.

\section{Conflicts of interest}

The authors declare no financial or other potential conflicts of interest.

\section{REFERENCES}

Arbuckle MR, McClain MT, Rubertone MV, Scofield RH, et al. (2003). Development of autoantibodies before the clinical onset of systemic lupus erythematosus. N. Engl. J. Med. 349: 1526-1533.

Bamberger CM, Schulte HM and Chrousos GP (1996). Molecular determinants of glucocorticoid receptor function and tissue sensitivity to glucocorticoids. Endocr. Rev. 17: 245-261.

Beck IM, Vanden Berghe W, Vermeulen L, Yamamoto KR, et al. (2009). Crosstalk in inflammation: the interplay of glucocorticoid receptor-based mechanisms and kinases and phosphatases. Endocr. Rev. 30: 830-882.

Castro M and Moreira AC (2002). Diagnóstico laboratorial da síndrome de Cushing. Arq. Bras. Endocrinol. Metab. 46: 97-105.

Cavalcante LO, Melo MR, Dinis VG, Castro RB, et al. (2010). Quantitation of glucocorticoid receptor alpha and NF-kB pathway mRNA and its correlation with disease activity in rheumatoid arthritis patients. Genet. Mol. Res. 9: 2300-2310.

Cobra JF, Melo MR, Faria CD, Longui CA, et al. (2009). Simultaneous evaluation of in vivo glucocorticoid sensitivity and expression of glucocorticoid receptor alpha-isoform in rheumatoid arthritis patients. Arq. Bras. Endocrinol. Metabol. 53: 24-30.

De Bosscher K, Vanden Berghe W and Haegeman G (2001). Glucocorticoid repression of AP-1 is not mediated by competition for nuclear coactivators. Mol. Endocrinol. 15: 219-227.

Faria CD and Longui CA (2006). Molecular aspects of glucocorticoid sensitivity. Arq. Bras. Endocrinol. Metabol. 50: 983-995.

Faria CD, Cobra JF, Sousa E Silva, Melo MR, et al. (2008). A very low dose intravenous dexamethasone suppression test as an index of glucocorticoid sensitivity. Horm. Res. 69: 357-362.

Gladmann DD, Ibañez D and Urowitz MB (2002). Systemic lupus erythematosus disease activity index 2000. J. Rheumatol. 29: 288-291.

Hochberg MC (1997). Updating the American College of Rheumatology revised criteria for the classification of systemic lupus erythematosus. Arthritis Rheum. 40: 1725.

Koper JW, Stolk RP, de Lange P, Huizenga NA, et al. (1997). Lack of association between five polymorphisms in the human glucocorticoid receptor gene and glucocorticoid resistance. Hum. Genet. 99: 663-668.

Lee YM, Fujiwara J, Munakata Y, Ishii T, et al. (2004). A mutation of the glucocorticoid receptor gene in patients with systemic lupus erythematosus. Tohoku J. Exp. Med. 203: 69-76.

Li LB, Goleva E, Hall CF, Ou LS, et al. (2004). Superantigen-induced corticosteroid resistance of human T cells occurs through activation of the mitogen-activated protein kinase kinase/extracellular signal-regulated kinase (MEK-ERK) pathway. J. Allergy Clin. Immunol. 114: 1059-1069.

Liddle GW (1960). Tests of pituitary-adrenal suppressibility in the diagnosis of Cushing's syndrome. J. Clin. Endocrinol. Metab. 20: 1539-1560.

Matthews JG, Ito K, Barnes PJ and Adcock IM (2004). Defective glucocorticoid receptor nuclear translocation and altered histone acetylation patterns in glucocorticoid-resistant patients. J. Allergy Clin. Immunol. 113: 1100-1108.

McKay LI and Cidlowski JA (1999). Molecular control of immune/inflammatory responses: interactions between nuclear factor-К B and steroid receptor-signaling pathways. Endocr. Rev. 20: 435-459.

Melo MR, Faria CD, Melo KC, Rebouças NA, et al. (2004). Real-time PCR quantitation of glucocorticoid receptor alpha isoform. BMC. Mol. Biol. 5: 19.

Neeck G, Kluter A, Dotzlaw H and Eggert M (2002). Involvement of the glucocorticoid receptor in the pathogenesis of rheumatoid arthritis. Ann. N. Y. Acad. Sci. 966: 491-495.

Oakley RH, Sar M and Cidlowski JA (1996). The human glucocorticoid receptor beta isoform. Expression, biochemical properties, and putative function. J. Biol. Chem. 271: 9550-9559.

Oakley RH, Jewell CM, Yudt MR, Bofetiado DM, et al. (1999). The dominant negative activity of the human glucocorticoid receptor beta isoform. Specificity and mechanisms of action. J. Biol. Chem. 274: 27857-27866.

Oelke K and Richardson B (2002). Pathogenesis of lupus. Arthritis Rheum. 47: 343-345. 
Petri M (2002). Epidemiology of systemic lupus erythematosus. Best. Pract. Res. Clin. Rheumatol. 16: 847-858.

Piotrowski P, Burzynski M, Lianeri M, Mostowska M, et al. (2007). Glucocorticoid receptor beta splice variant expression in patients with high and low activity of systemic lupus erythematosus. Folia Histochem. Cytobiol. 45: 339-342.

Rahman P, Gladman DD, Urowitz MB, Hallett D, et al. (2001). Early damage as measured by the SLICC/ACR damage index is a predictor of mortality in systemic lupus erythematosus. Lupus 10: 93-96.

Schaaf MJ and Cidlowski JA (2003). Molecular determinants of glucocorticoid receptor mobility in living cells: the importance of ligand affinity. Mol. Cell Biol. 23: 1922-1934.

Sousa e Silva, Longui CA, Rocha MN, Faria CD, et al. (2010). Prolonged physical training decreases mRNA levels of glucocorticoid receptor and inflammatory genes. Horm. Res. Paediatr. 74: 6-14.

Webster JC, Oakley RH, Jewell CM and Cidlowski JA (2001). Proinflammatory cytokines regulate human glucocorticoid receptor gene expression and lead to the accumulation of the dominant negative beta isoform: a mechanism for the generation of glucocorticoid resistance. Proc. Natl. Acad. Sci. U. S. A. 98: 6865-6870.

Winter WE and Harris NS (2008). Handbook of Diagnostic Endocrinology. In: Laboratory Approaches to Diseases of the Adrenal Cortex and Adrenal Medulla (Winter WE, Sokoll I and Jialal LJ, eds.). 2nd edn. AACC Press, Washington, 75-138.

Wong HK, Kammer GM, Dennis G and Tsokos GC (1999). Abnormal NF- $\kappa$ B activity in T lymphocytes from patients with systemic lupus erythematosus is associated with decreased p65-RelA protein expression. J. Immunol. 163: $1682-1689$. 